\title{
The role of enactment in prospective remembering
}

\author{
EVELYN G. SCHAEFER, MARIA V. KOZAK, and KERRY SAGNESS \\ University of Winnipeg, Winnipeg, Manitoba, Canada
}

\begin{abstract}
This study investigated, in a laboratory setting, whether prospective memory (remembering to perform intended actions in the future) would be improved by self-enactment of the to-be-remembered tasks. The subjects, 45 university students, were asked to remember later to perform five tasks that they initially enacted themselves, watched the experimenter perform, or had described to them. These tasks were to be performed, ostensibly in preparation for the next subject, at the end of $30 \mathrm{~min}$ of filler activity, which was presented as the experimental task. Surprisingly, self-enactment produced the poorest prospective remembering. Speculative explanations are offered in terms of both metacognitive expectations about memory and output-monitoring deficiencies.
\end{abstract}

Whereas retrospective memory involves the remembering of information acquired in the past, prospective memory involves remembering at some time in the future to perform intended actions (Meacham \& Leiman, 1982). Failures of prospective memory are among the most frequently reported types of everyday memory difficulties (Cavanaugh, Grady, \& Perlmutter, 1983; Crovitz \& Daniel, 1984; Lovelace \& Twohig, 1990) and often have serious consequences.

Beyond the application of external memory aids (see Intons-Peterson \& Newsome, 1992, for a review of the effectiveness of such aids), is there anything that can be done to improve prospective remembering? Are there any elaborative encoding operations that might enhance prospective memory performance? One candidate is selfinvolvement. Tests of retrospective memory show that material that is self-referent (Rogers, Kuiper, \& Kirker, 1977) or is self-generated (Slamecka \& Graf, 1978) is better remembered than material that is not.

Subjects tend to remember a series of actions (e.g., snapping fingers, bouncing a ball) that they themselves performed in the past (SPTs, subject-performed tasks; Cohen, 1981 ) better than those that were presented only verbally for free recall (for reviews, see Cohen, 1989; Engelkamp \& Cohen, 1991; and Engelkamp \& Zimmer, 1989). Selfperformance of tasks has been found in some cases to improve recall significantly more than does watching the actions being performed by a model (EPTs, experimenterperformed tasks; Engelkamp \& Zimmer, 1985). Moreover, imagined as well as actual self-enactment of tasks has been found to increase their recall (Helstrup, 1987; Saltz \& Donnenwerth-Nolan, 1981).

We are grateful to W. Josephson and G. Becker for their comments on a draft of this article and to the reviewers for their helpful suggestions. Correspondence should be addressed to E. G. Schaefer, Department of Psychology, University of Winnipeg, Winnipeg, MB, R3B 2E9 Canada (e-mail: schaefer@io.uwinnipeg.ca).

—Accepted by previous editor, Geoffrey R. Loftus
The generally consistent findings regarding the enhancing effects of enactment for retrospective recall lead to an obvious question: Does enactment improve retention of acts intended for future performance? This question has been addressed in recent studies, with less consistent results.

Koriat, Ben-Zur, and Nussbaum (1990) found that subjects presented with verbal descriptions of minitasks for future recall showed superior retention when they were required to enact rather than verbally report them at test. When expectations regarding report mode and actual mode of report were made incongruent, memory was better for tasks that the subjects expected to have to perform, regardless of report mode. The benefits of an enactment test mode, however, have not always been confirmed (Brooks \& Gardiner, 1994) and may depend on age (Norris \& West, 1993) and on the nature of the to-beremembered actions (Kormi-Nouri, Nyberg, \& Nilsson, 1994). Nor has expectation of future enactment consistently been associated with enhanced retention of intended future actions (Brooks \& Gardiner, 1994). The beneficial effects of expectations of enactment may be a function of methodological considerations. There is some evidence that such expectation effects are found in betweensubjects but not in within-subjects designs (Engelkamp, 1997). The fact that different testing conditions have been employed across studies (e.g., varying retention and report intervals; free, serial, and cued recall) also makes conclusions regarding the effects of enactment on prospective remembering difficult.

Previous investigations of enactment effects in prospective memory characteristically have involved the retention of short sequences of unrelated, non-goal-derived minitasks, tested immediately or very soon after presentation. The end of the list and the experimenter's expectation of recall both serve as cues to signal the appropriate time for demonstrating retention of the tasks. Under such conditions, there is virtually no opportunity to forget the intention to perform the actions. Everyday prospective memory, however, typically involves self-cued remem- 
bering to perform goal-derived intended actions. There is generally a lengthier interval between the formation of the intention to perform the future action and the appropriate or chosen time for it, during which interval the nature of the to-be-performed task (i.e., its content) and/or the intention to perform it may be forgotten (cf. Harris, 1984; Kvavilashvili, 1992).

The present study addressed the question of the applicability of enactment as a strategy for improving everyday prospective remembering: Are we better at remembering to perform actions in the future if we first practice performing these actions? Naturalistic prospective memory tasks were designed for performance at the end of the experimental session. These tasks were not the main focus of the study, but were preparatory for the subject's own session and, allegedly, for that of the next subject. The verbal description of the to-be-performed tasks at the beginning of the session was either accompanied by subject enactment or not, and the number of prospective tasks completed at the end of the session was assessed. In order to determine the relative influence of self-production, as opposed to the observation of action, in the effects of enactment on prospective remembering, a group of subjects who initially watched the experimenter enact the tasks was also tested.

Whereas most earlier work investigating enactment effects in prospective memory has tested the retention of the content aspect of intended actions, the present study explored the retention of both the intention to perform and the content of intended future actions. To evaluate whether content of actions was still available in memory, independent of the forgetting of intentions to perform them, unexpected cued recall of the content of prospective tasks was tested postexperimentally.

\section{METHOD}

\section{Subjects}

Forty-five introductory psychology students (17 males and 28 females, mean age $=20.9$ years) participated in the study in partial fulfilment of course requirements. The subjects were assigned randomly to one of three experimental conditions, with the restriction that the ratio of males to females in each condition was approximately equal. The subjects were tested individually.

\section{Materials and Room Arrangement}

Test booklets, identical for all the subjects, were constructed, consisting of a sheet requesting background subject information, followed by the materials for two tasks: (1) a verbal passage was to be read and a simultaneous count made of both nouns and words containing a target letter combination, and then (2) a lengthy series of numbers was to be examined and target numbers detected and crossed out. The activities were designed so as to introduce items necessary for performance of the prospective tasks--that is, an electronic counter and bingo chips used for the tallying assignments, a cardholder delineating subject identification numbers, a pencil, and a stack of test booklets in envelopes. All task materials were in clear view and in easy reach of anyone seated at the work desk or about to leave the small testing room, and none stood out in an obvious way. Initial setup of the room was consistent across subjects.
A full description of the room arrangement, all prospective task materials, and their placement appears in the Appendix.

\section{Procedure}

The subjects were told that they were participating in an experiment on attentional processes involving searching for various word and number targets in different background material. They were informed that the experimenter would not be present while they were working. The five prospective tasks were introduced under the guise of preparatory tasks by means of the following instructions:

You are the first subject to be tested in this particular experimental condition. There are several things that you need to do [replaced by I need to do or that have been done for you in the appropriate conditions] in order to get ready for the experiment. Because I am testing several subjects at the same time I probably will not be here when you are finished [with] the experiment. Would you please do these same things before you leave the room so that the room will be ready for the next subject.

The manipulation specific to each condition was then introduced. The subjects in the performed condition had the prospective tasks described to them one at a time. Immediately after each description, they had to physically perform that action in preparation for their own upcoming session (e.g., "You need to take a brown envelope from the stack on the shelf and place it on the desk in front of you"). In the demonstrated condition, the experimenter described each prospective task and then subsequently performed it (e.g., "I need to take a brown envelope from the stack on the shelf and place it on the desk in front of you"). Subjects in the informed condition had each of the tasks described to them as having been completed already and, in fact, found such to be the case (e.g. "A brown envelope has been taken from the stack on the shelf and placed on the desk in front of you"). A short but natural pause was inserted between the descriptions of the tasks in this condition, in an attempt to compensate for the additional time between descriptions required for performance of the actions in the other two conditions. An exact description of the five tasks appears in the Appendix.

Across conditions, the order of the descriptions of the five tasks was held constant, and care was taken to use parallel wording in the descriptions for a given task. However, no mention was made of the exact number of prospective tasks to be performed, so as not to provide any numerical retrieval cues. The descriptions of the to-beperformed preparatory tasks were presented in an informal manner, so as not to draw attention to their relevance. The assignment of each subject as the first subject was included so that the initial state of preparedness of the task materials found by subjects in all conditions would not be attributable to the actions of a previous subject, which might have differentially affected motivational levels across conditions. The prospective tasks were introduced only once, and no reminder was provided at the end of the instructions.

All subjects were next informed that they were to work on the task booklet for $30 \mathrm{~min}$. They were told that, at the sound of a prearranged distinctive door knock (without entry by the signaler), they were to stop working and open a final instructions envelope. This envelope contained a note instructing them to perform two final tasks: to put all papers in the original brown envelope and then to deposit this envelope in a specific location by the door. The final sentence of the note was worded: "If the experimenter has not returned, having completed the requested tasks, you are free to leave." The term requested tasks, which could refer to either the prospective tasks or the final cleanup tasks, was deliberately ambiguous. Lastly, subjects were instructed to begin work, and the experimenter left the room.

Thirty min later, the door knock signal was given. The subjects were allowed to leave the room at their own pace. Upon exiting, they were intercepted by the experimenter and asked to complete a short questionnaire at a nearby desk, out of sight of the room. The first question reminded subjects that they had been asked at the outset 
Table 1

Proportions of Subjects Who Showed Total, Partial, or No Prospective Task Performance

\begin{tabular}{|c|c|c|c|}
\hline \multirow[b]{2}{*}{ Encoding Condition } & \multicolumn{3}{|c|}{ Prospective Task Performance } \\
\hline & $\begin{array}{c}\text { Total: } \\
5 \text { Tasks } \\
\text { Performed }\end{array}$ & $\begin{array}{c}\text { Partial: } \\
\text { 1-4 Tasks } \\
\text { Performed }\end{array}$ & $\begin{array}{c}\text { None: } \\
0 \text { Tasks } \\
\text { Performed }\end{array}$ \\
\hline Instructed & .33 & .67 & .00 \\
\hline Performed & .13 & .33 & .53 \\
\hline Demonstrated & .13 & .53 & .33 \\
\hline
\end{tabular}

Note- $n=15$ subjects per cell.

of the experiment to perform activities to prepare for the next subject and asked them to list these actions. Further questions inquired whether they had performed any of the actions and asked for a description of any strategies they had used to remember to perform these tasks and, if applicable, for their reasons for failing to perform them.

\section{RESULTS}

Because remembrance of the intention to perform the tasks was of greater interest than was performance of the tasks in the exact manner described, a lenient scoring system was implemented, in which all responses that indicated the subject had attempted to perform a task, including those deviating from the instructed method, were counted as correct. (A similar significant pattern of results was found under strict scoring.)

A one-way analysis of variance indicated that there were significant differences among the means for the three types of encoding conditions $[F(2,42)=7.16, p<$ $.0025]$. Post hoc Tukey's tests revealed that subjects who had simply been instructed to perform the prospective tasks remembered to do more of them $(M=3.87, s=1.19)$ at the end of the experiment than did those who had already performed them once $(M=1.47, s=1.96)$ in preparation for their own session $(p<.01)$. The mean number of prospective tasks performed by subjects who had watched the experimenter demonstrate them $(M=2.53$, $s=1.96$ ) was not significantly different from that in either of the other two conditions $(p>.05)$.

Whereas $20 \%$ of the subjects in the study performed all five prospective tasks, the majority $(51.1 \%)$ remembered to perform some but not all of them. More than one fourth of the subjects $(28.9 \%)$, however, performed none of the tasks; most of these complete failures occurred in the performed condition. The proportions of subjects showing the three types of response performance (total, partial, none) in each of the encoding conditions are displayed in Table 1. A chi-square analysis of the proportion of subjects who showed perfect, partial, and no performance of the prospective tasks in each of the encoding conditions revealed that the pattern of responding differed across encoding conditions $\left[\chi^{2}(4)=11.18, p<.05\right]$.

The first question on the postexperimental questionnaire asked subjects to recall what preparatory activities they had been asked to perform at the end of the session. Of the 36 subjects overall who did not perform all five of the prospective tasks at the end of the session, $19(52.8 \%)$ were able to recall more tasks than had been performed. Table 2 shows the mean number of tasks recalled as a function of encoding condition and type of response performance. The postexperimental cue had the greatest effect for subjects who had initially failed completely to perform any of the tasks. Postexperimental cued recall of prospective tasks by such subjects in both the performed and demonstrated conditions was now significantly greater than zero $[t(7)=3.08, p<.01$ and $t(4)=4.48, p<.01$, respectively]. For those subjects who had completed some (one to four) of the prospective tasks, postexperimental recall of them did not differ as a function of whether they had originally performed, watched a demonstration of, or been instructed about the tasks $[F(2,20)=2.37, p>.05]$.

For the subjects who had failed to perform any of the prospective tasks but were able to recall some tasks when cued on the questionnaire, such recall was the first evidence of their retention of the nature of the tasks to be performed. For these subjects, the experimenter-provided cue appears to have brought recall scores up to a level comparable to that for self-cued remembering of the tasks. The mean cued recall scores for the subjects who failed to perform any of the prospective tasks but subsequently recalled at least one in the performed and demonstrated conditions were $3.40(n=5)$ and $2.20(n=5)$, respectively. For the subjects in the performed and demonstrated conditions who initially performed at least one task at the end of the session, the corresponding mean performance scores

Table 2

Mean Number of Tasks Recalled Postexperimentally as a Function of Encoding Condition and Prospective Task Performance

\begin{tabular}{|c|c|c|c|c|c|c|}
\hline \multirow[b]{3}{*}{ Encoding Condition } & \multicolumn{6}{|c|}{ Prospective Task Performance } \\
\hline & \multicolumn{2}{|c|}{$\begin{array}{c}\text { Total: } \\
5 \text { Tasks } \\
\text { Performed }\end{array}$} & \multicolumn{2}{|c|}{$\begin{array}{c}\text { Some: } \\
\text { 1-4 Tasks } \\
\text { Performed }\end{array}$} & \multicolumn{2}{|c|}{$\begin{array}{c}\text { None: } \\
\text { 0 Tasks } \\
\text { Performed }\end{array}$} \\
\hline & $M$ & $n$ & $M$ & $n$ & $M$ & $n$ \\
\hline Instructed & 5.00 & 5 & 3.90 & 10 & * & 0 \\
\hline Performed & 5.00 & 2 & 3.00 & 5 & 2.13 & 8 \\
\hline Demonstrated & 5.00 & 2 & 4.00 & 8 & 2.20 & 5 \\
\hline
\end{tabular}

*Given that all the subjects in the instructed condition performed at least one task, this cell is blank. 
(indicative of task retention) were $3.14(n=7)$ and 3.80 $(n=10)$, respectively. All the subjects in the instructed condition remembered to perform at least one task at the end of the session ( $M=3.87$ tasks). It appears that the subjects who recalled the content of the prospective tasks only after experimenter cuing did not differ all that much, in the mean number of tasks they retained, from those who remembered on their own to perform them.

In response to a question about strategies used to remember to perform the prospective tasks, few subjects across conditions $(20.0 \%)$ reported using external strategies, such as "looking around the room" or "searching for cues in the vicinity as to what things were needed." More subjects $(35.6 \%)$ reported relying on internal strategies, such as repetition, imaginally retracing the initial part of the session, trying to remember the number of tasks as a cue, and so forth. Most frequently, however, subjects $(44.4 \%)$ did not report using any strategies.

\section{DISCUSSION}

Contrary to predictions, the subjects who initially enacted prospective tasks that were to be performed later in the experimental session were less likely to perform them subsequently than were the subjects who either watched them being demonstrated or had them verbally described at the beginning of the session. In addition, when subjects first observed enactment of the tasks by the experimenter, prospective memory performance was not enhanced over that found when they received only verbal instructions.

It appears that the subjects' prospective memory in this study very often operated in an all-or-none fashion, with more subjects failing to perform any of the tasks than remembering to perform all of them. The pattern of responding differed significantly across the encoding conditions. Whereas a majority of the subjects who had enacted the tasks forgot subsequently to perform even a single one of them, all of the verbally instructed subjects remembered to perform at least one.

The subjects' prospective memory failures appeared to be more a function of their forgetting the intention to perform the tasks and/or of their failure to cue themselves to remember than of their forgetting the specific nature of the tasks to be performed. Subjects who failed to perform any of the tasks generally were able, upon postexperimental cuing, to demonstrate significant recall of the content of tasks they had forgotten to perform. In fact, their retention of task content was generally equivalent to that of subjects whose performance of the prospective tasks at the end of the session was indicative of such retention, which suggests that retention of intention and content may be independent. Interestingly, for subjects who had failed to perform any of the tasks, experimenter-cued recall of the content of the tasks that were to have been performed, conducted in an environment different from the testing room and without the availability of the task objects as external cues for remembering, was superior to prospective memory performance in the testing room with these cues present. The present findings are consistent with those of Kvavilashvili (1987), who found remembering of an intention to pass on a message to be statistically unrelated to remembering the specific content of the message.

Given the surprising failure of subject enactment as a prospective memory aid and its puzzling debilitating consequences for such memory, we conducted a partial replication and extension of the experiment. Under conditions that basically replicated the original study, subjects who initially enacted five prospective tasks again performed significantly fewer $(p<.01)$ of the tasks $(M=2.87, n=$ $15)$ than did subjects in an instructed condition $(M=$ $4.53, n=15$ ). Moreover, enacting subjects' cued recall of the tasks on a postexperimental questionnaire was again significantly greater than their performance of the tasks. For two additional groups of subjects, the prospective tasks were changed to ones that employed the same objects but were unrelated to a common preparatory goal (e.g., setting a manual counter on its end, removing the top of a sharpener). Although prospective remembering of these unrelated tasks was unaffected by enactment and equivalent to that for related tasks presented without enactment, the possibility of ceiling effects could not be ruled out.

The debilitating effects of enactment on prospective remembering found in the present study and its replication stand in direct opposition to the facilitative role that enactment has been widely demonstrated to play in retrospective remembering. Subjects who, at time of encoding, have themselves enacted activities with real objects (see, e.g., Cohen, 1981) or mimed actions with imaginary objects (see, e.g., Brooks \& Gardiner, 1994; Engelkamp, Zimmer, \& Biegelmann,1993) and those who have watched others (see, e.g., Cohen, Peterson, \& MantiniAtkinson, 1987), imagined others (see, e.g., Saltz \& Donnenwerth-Nolan, 1981), or imagined themselves (Helstrup, 1987) performing activities have all been shown to have remembered the actions better than when they had only had them verbally described. If enactment results in optimal nonstrategic processing (Cohen, 1981) or in the establishment of a richer trace either as a function of a motoric coding dimension or store (Engelkamp \& Zimmer, 1985; Saltz, 1988) or as a function of greater selfinvolvement (Helstrup, 1986), one would expect that enactment, particularly self-enactment, of to-be-remembered activities should likewise lead to prospective remembering that is enhanced relative to that following verbal instructions alone.

Moreover, the finding that self-enactment actually hindered prospective remembering for related, preparatory tasks is particularly curious. In retrospective remembering of enacted tasks the reverse appears to be the case. Under enactment conditions, retention of tasks that can be organized in sets (Bäckman, Nilsson, \& Chalom, 1986) or that serve a common purpose (Brewer \& Dupree, 1983; Glover, Timme, Deyloff, \& Rogers, 1987) has been found to be superior to retention of discrete, unrelated actions.

Engelkamp (1997) has found that subjects who enacted a series of minitasks at encoding with the expecta- 
tion and requirement of performing them again on an immediate free recall test were no more likely to remember the tasks than were subjects who also expected and received a performance test mode but did not enact the tasks at encoding. In fact, such enacting subjects recalled fewer of the minitasks than did enacting subjects who expected and received a verbal test. According to Engelkamp, these negative effects of enactment are the result of interference effects that arise when subjects at encoding must engage in both performance-planning and performance-execution processes for the immediately enacted action while simultaneously planning for future action at test, leading to a repetition of the planning component and a weakening of the distinctiveness of enacted actions, relative to verbally presented tasks.

This explanation of the negative effects of enactment in prospective remembering does not apply well in the present study. Whereas lack of distinctiveness might induce poorer retention of the content of prospective tasks, the repetition of planning processes might be expected to increase the likelihood of remembering intentions to perform future actions. Given that enacting subjects in the present study seemed to have had available in memory the content of the required prospective activities and that watching the actions being performed and simultaneously planning to perform them did not lead to a similar significant impairment of retention, an explanation in terms of interference effects from the repetition of planning processes seems untenable.

The finding that enactment impaired prospective remembering in this study is open to two further speculative interpretations, one related to the subjects' expectations or beliefs regarding their prospective performance (i.e., a metacognitive-expectation explanation; cf. Devolder \& Pressley, 1991), and the other related to output monitoring (cf. Koriat \& Ben-Zur, 1988; Koriat, Ben-Zur, \& Druch, 1991).

If the subjects who initially enact the tasks are more likely to expect prospective remembering to be easy as a result of such enactment, they may spend less time and effort in encoding, rehearsing, and/or reminding themselves about the intention to perform the tasks than do subjects in other conditions (cf. Helstrup, 1987). As a result, performance should suffer. This hypothesis has some experimental support from studies in which the relationship between people's beliefs about their memories (i.e., metamemory) and their prospective memory performance are investigated. Correlations between prospective memory performance and various measures of metamemory have often been found to be negative, with increased confidence and trust in one's memory abilities associated with prospective memory failures for both children and adults (Beal, 1988; Dobbs \& Rule, 1987; Moscovitch \& Minde, personal communication, and cited in Harris, 1984).

In particular, subjects have been found to be unreliable in their metacognitive assessments of the recallability of self-performed tasks (Cohen, 1988) and to judge such tasks to be far easier than comparable recall tasks (Cohen,
1983). Subjects have been reported to express surprise after poor performance on retrospective tests of SPT retention, having expected to remember nearly everything with very little effort (Lichty, Bressie, \& Krell, 1988). It may be that subjects perceive retention of enacted actions to be so simple that they choose not to engage in active encoding and/or rehearsal operations (Helstrup, 1987), or they may even lack any appropriate strategies for the remembrance of SPTs (Lichty et al., 1988).

The metacognitive-expectation hypothesis receives some support from this study's questionnaire data regarding mnemonic strategies employed. Internal strategies were reportedly used more frequently than external strategies (cf. Maylor, 1990); however, the majority of the subjects did not report using any strategies. Several subjects who had enacted tasks initially even reported that prospective remembering was easy because they had performed the activities before and that, therefore, no specific strategies were needed.

The metacognitive-expectation hypothesis warrants further investigation. The assessment of metacognitive beliefs a priori to prospective memory tasks involving enactment and the experimental manipulation of such beliefs seem fruitful avenues for research. Certainly, if metacognitive considerations are found to be of significance in such memory tasks, then arguments that SPTs involve nonstrategic (i.e., automatic) processing (Cohen, 1981) would be less convincing. ${ }^{1}$

An alternative, but not necessarily mutually exclusive, explanation of the results postulates that prior enactment might lead to a deficiency in output monitoring. Output monitoring involves the checking of which intended acts have been and which have not yet been done. One of the consequences of deficient output monitoring is failing to perform an intended action as a result of a false belief that it has already been completed (Sher, Frost, \& Otto, 1983). Subjects have been found to confuse memories of real and imagined events (Johnson, 1988). They have been shown to confuse memories of doing and memories of imagining doing, tending to assume that an activity has been performed when it was only imagined (Anderson, 1984). Such findings suggest that subjects who have initially enacted prospective tasks may be more likely than those who have not to assume, as the result of the memory of their actions, that the required tasks have already been performed and thus be less likely to engage in checking, at the appropriate later time, as to whether, in fact, the tasks have been completed.

The present study is one of the few providing for a quantitative index of prospective memory performance by testing future remembering of multiple natural actions rather than of single intended acts. The effects of motoric activity on prospective remembering in a controlled setting involving natural tasks has been investigated in one other study (Vortac, Edwards, Fuller, \& Manning, 1993). As part of a simulation project (reported subsequent to the collection of data in the present study) that assessed the effects of the automation of air traffic control on cogni- 
tive functioning and performance, air traffic controllers had to remember to act on postponed pilots' requests. Delay of performance was self-governed and short (mean latencies under $3 \mathrm{~min}$ ). Controllers who wrote on or repositioned flight strips (formatted slips of paper for recording flight data) were less likely than those who were restricted from doing so to perform the prospective tasks and were less punctual in performing those tasks that they did remember to do. These results, found with a specialized subject population group, support the findings of the present study .

Evidence is mounting that enactment at encoding can lead to the impairment of prospective remembering. Both task content (Engelkamp, 1997) and performance intentions (Vortac et al., 1993) are more poorly remembered over short intervals after enactment. In the present investigation, enactment at encoding impaired the memory for intentions to perform actions $30 \mathrm{~min}$ later. These findings bring into question the generality of folk wisdom's old adage that "you will remember to do something better if you do it yourself." It appears that, in a search for mnemonic aids to prospective remembering, we may need to look further than self-enactment.

\section{REFERENCES}

ANDERSON, R. (1984). Did I do it or did I only imagine doing it? Journal of Experimental Psychology: General, 113, 594-613.

BäCKMAN, L., NilsSon, L.-G., \& Chalom, D. (1986). New evidence on the nature of the encoding of action events. Memory \& Cognition, 14, 339-346.

BEAL, C. R. (1988). The development of prospective memory skills. In M. M. Gruneberg, P. E. Morris, \& R. N. Sykes (Eds.), Practical aspects of memory: Current research and issues (Vol. 1, pp. 366-370). Chichester, U.K.: Wiley.

BREWER, W. F., \& DUPREE, D. A. (1983). Use of plan schemata in the recall and recognition of goal-directed actions. Journal of Experimental Psychology: Learning, Memory, \& Cognition, 9, 117-129.

Brooks, B. M., \& GARdiner, J. M. (1994). Age differences in memory for prospective compared with retrospective subject-performed tasks. Memory \& Cognition, 22, 27-33.

Cavanaugh, J. C., Grady, J. G., \& Perlmutter, M. (1983). Forgetting and use of memory aids in 20 to 70 year olds' everyday life. International Joumal of Aging \& Human Development, 17, 113-122.

CoHEN, R. L. (1981). On the generality of some memory laws. Scandinavian Journal of Psychology, 22, 267-281.

CoHen, R. L. (1983). The effect of encoding variables on the free recall of words and action events. Memory \& Cognition, 11, 575-582.

COHEN, R. L. (1988). Metamemory for words and enacted instructions: Predicting which items will be recalled. Memory \& Cognition, 16, 452-460.

CoHen, R. L. (1989). Memory for action events: The power of enactment. Educational Psychology Review, 1, 57-80.

Cohen, R. L., Peterson, M., \& Mantini-Atkinson, T. (1987). Interevent differences in event memory: Why are some events more recallable than others? Memory \& Cognition, 15, 109-118.

Crovitz, H. F., \& Daniel, W. F. (1984). Measurements of everyday memory: Toward the prevention of forgetting. Bulletin of the Psychonomic Society, 22, 413-414.

Devolder, P. A., \& Pressley, M. (1991). Memory complaints in younger and older adults. Applied Cognitive Psychology, 5, 443-454.

Dobis, A. R., \& Rule, B. G. (1987). Prospective memory and selfreports of memory abilities in older adults. Canadian Journal of Psychology, 41, 209-222.

ENGELKaMP, J. (1997). Memory for to-be-performed tasks versus memory for performed tasks. Memory \& Cognition, 25, 117-124.
ENGelKamp, J., \& Cohen, R. L. (1991). Current issues in memory of action events. Psychological Research, 53, 175-182.

ENGELKAMP, J., \& ZIMMER, H. D. (1985). Motor programs and their relation to semantic memory. German Journal of Psychology, 9, 239-254.

ENGEL KAMP, J., \& ZimMER, H. D. (1989). Memory for action events: A new field of research. Psychological Research, 51, 153-157.

ENGELKAMP, J., ZimmeR, H. D., \& BiegelmanN, U. E. (1993). Bizarreness effects in verbal tasks and subject-performed tasks. European Journal of Cognitive Psychology, 5, 393-415.

Glover, J. A., Timme, V., DeYloff, D., \& Rogers, M. (1987). Memory for student-performed tasks. Journal of Educational Psychology, 79, 445-452.

HARRIS, J. E. (1984). Remembering to do things: A forgotten topic. In J. E. Harris \& P. E. Morris (Eds.), Everyday memory, actions and absent-mindedness (pp. 71-92). New York: Academic Press.

HeLsTRUP, T. (1986). Separate memory laws for recall of performed acts? Scandinavian Journal of Psychology, 27, 1-29.

HelsTRUP, T. (1987). One, two, or three memories? A problem-solving approach to memory for performed acts. Acta Psychologica, 66, 37-68.

Intons-Peterson, M. J., \& Newsome, G. L. (1992). External memory aids: Effects and effectiveness. In D. J. Herrmann, H. Weingartner, A. Searleman, \& C. McEvoy (Eds.), Memory improvement: Implications for memory theory (pp. 101-121). New York: Springer-Verlag.

JoHNSON, M. K. (1988). Reality monitoring: An experimental phenomenological approach. Journal of Experimental Psychology: General, 117, 390-394.

Koriat, A., \& Ben-Zur, H. (1988). Remembering that I did it: Processes and deficits in output monitoring. In M. M. Gruneberg, P. E. Morris, \& R. N. Sykes (Eds.), Practical aspects of memory: Current research and issues (Vol. 1, pp. 203-208). Chichester, U.K.: Wiley.

Koriat, A., Ben-Zur, H., \& DRUCH, A. (1991). The contextualization of input and output events in memory. Psychological Research, 53, 260-270.

Koriat, A., Ben-Zur,.H., \& Nussbaum, A. (1990). Encoding information for future action: Memory for to-be-performed tasks versus memory for to-be-recalled tasks. Memory \& Cognition, 18, 568-578.

Kormi-NOURI, R., NYBERG, L., \& NiLSSON, L.-G. (1994). The effect of retrieval enactment on recall of subject-performed tasks and verbal tasks. Memory \& Cognition, 22, 723-728.

KVAVILASHVILI, L. (1987). Remembering intention as a distinct form of memory. British Journal of Psychology, 78, 507-518.

KVAVILASHVILI, L. (1992). Remembering intentions: A critical review of existing experimental paradigms. Applied Cognitive Psychology, 6, 507-524.

Lichty, W., Bressie, S., \& Krell, R. (1988). When a fork is not a fork: Recall of performed activities as a function of age, generation, and bizarreness. In M. M. Gruneberg, P. E. Morris, \& R. N. Sykes (Eds.), Practical aspects of memory: Current research and issues (Vol. 2, pp. 506-511). Chichester, U.K.: Wiley.

LoVELACE, E. A., \& TwoHig, P. T. (1990). Healthy older adults' perceptions of their memory functioning and use of mnemonics. Bulletin of the Psychonomic Society, 28, 115-118.

MAYLOR, E. A. (1990). Age and prospective memory. Quarterly Journal of Experimental Psychology, 42A, 471-493.

Meacham, J. A., \& Leiman, B. (1982). Remembering to perform future actions. In U. Neisser (Ed.), Memory observed (pp. 327-336). San Francisco: Freeman.

NoRRIS, M. P., \& WEST, R. L. (1993). Activity memory and aging: The role of motor retrieval and strategic processing. Psychology \& Aging, 8, 81-86.

Rogers, T. B., KuIPER, N. A., \& Kirker, W. S. (1977). Self-reference and the encoding of personal information. Journal of Personality \& Social Psychology, 35, 677-688.

SALTZ, E. (1988). The role of motoric enactment (m-processing) in memory for words and sentences. In M. M. Gruneberg, P. E. Morris, \& R. N. Sykes (Eds.), Practical aspects of memory: Current research and issues (Vol. 1, pp. 408-414). Chichester, U.K.: Wiley.

Saltz, E., \& Donnenwerth-Nolan, S. (1981). Does motoric imagery facilitate memory for sentences? A selective interference test. Journal of Verbal Learning \& Verbal Behavior, 20, 322-332. 
SheR, K. J., Frost, R. O., \& OtTo, R. (1983). Cognitive deficits in compulsive checkers: An exploratory study. Behavior Research \& Therapy, 21, 357-363.

SlameCKa, N. J., \& Graf, P. (1978). The generation effect: Delineation of a phenomenon. Journal of Experimental Psychology: Human Learning \& Memory, 4, 592-604.

Vortac, O. U., EdWards, M. B., Fuller, D. K., \& Manning, C. A. (1993). Automation and cognition in air traffic control: An empirical investigation. Applied Cognitive Psychology, 7, 631-651.

\section{NOTE}

1. We wish to thank the reviewer, Asher Koriat, who suggested this important theoretical implication of positive metacognitive effects in the retention of SPTs.

\section{APPENDIX \\ Room Arrangement, Materials, and Prospective Tasks}

A small metal flipchart cardholder containing a set of numbered pages was used to indicate the subject's identification number, which was required on the subject information sheet. A Leghigh Valley Remote Points Counter, operated by a handheld remote control, and bingo chips were used to count nouns and words with target letter combinations, respectively. The cardholder, counter, and bingo chips, as well as a pencil, two identical 5-cm-high cylindrical pencil sharpeners, a box containing four sealed bags each filled with 65 bingo chips, and a dish to hold the chips were used in the prospective tasks.

Test booklets were each placed inside a brown manila envelope, and a stack of these envelopes placed on a shelf above the work desk, along with the box of bingo chip bags. The flipchart and a pencil sharpener were placed on a desk beside the work desk. The counter, its control, and the dish were located on the work desk. Also on the work desk were: (1) in the upper left corner, a stack of white envelopes, each labeled "Final Instructions"; (2) immediately to the left of the dish, a slotted cardboard box into which bingo chips were to be dropped during counting; and (3) just in front of the seating area, the pencil. The two desks and shelf all held other office materials (e.g., books, a desk organizer, pens, rulers, etc.), in addition to the prospective task materials.

The description of each of the following prospective tasks was held parallel across conditions. Subjects in the performed condition were told "You need to ....," and the description of the required action followed, with subjects subsequently performing the requisite action. Subjects in the demonstrated condition were told "I need to . . . ., followed by the experimenter's performance of the described action. In the instructed condition, all prospective task materials were displayed in ac- cordance with completed tasks, and the experimenter described each requisite action in turn as having been completed (e.g., "The pencil has been sharpened").

1. Subject identification card exposure on flipchart cardholder. The subjects were informed that their subject identification number was provided on the cardholder. The action de scribed was "expose your correct subject number by flipping the top blank card to the left over the rings of the cardholder." For all subjects, the number disclosed was 1, corroborating the deception that the subject was the first person to be tested.

2. Task-booklet envelope placement. This action was "to remove a brown envelope from the stack on the shelf and place it on the desk in front of you."

3. Bingo chip placement. This action was "to take a bag of bingo chips from the box on the shelf, open it, and pour the chips into the dish."

4. Counter resetting. Subjects in the performed and demonstrated conditions found the counter at some number other than zero, and the resetting activity (involving switching a toggle and operating the remote control) was described as needing to be performed by the subject or experimenter, respectively. The counter was set at zero for informed subjects, who received a description of the resetting activity as having been performed.

5. Pencil sharpening. The action was "to sharpen the pencil in front of you with the sharpener on that (the side) desk." In the performed and demonstrated conditions, the graphite pencil provided was unbroken but in need of sharpening. Once the activity was performed, the experimenter replaced the sharpener to its original position. Informed subjects were provided with a freshly sharpened pencil.

Note: All five tasks were designed so that, upon room inspection, their accomplishment could easily be discerned. Correct performance was indicated by the appearance of (1) a flip of the subject identification card to expose the next number, (2) an unopened task booklet envelope on the work desk, (3) the dish filled with bingo chips (the counting task ensured that the original supply of bingo chips was sufficiently depleted during the session so as to make it obvious whether refilling had occurred), and (4) the counter reset to zero. The assessment of the sharpening task required the use of two identical sharpeners with attached opaque containers for catching shavings. As the subject began working, the experimenter, before leaving the room, surreptitiously pocketed the sharpener on the desk and replaced it with a clean sharpener. The replacement sharpener was inspected subsequently for shavings.

(Manuscript received September 13, 1996; revision accepted for publication May 9, 1997.) 